\title{
The role of syllabic structure in French visual word recognition
}

\author{
AÏCHA ROUIBAH \\ Institut des Sciences Cognitives, Lyon, France \\ and \\ MARCUS TAFT \\ University of New South Wales, Sydney, Australia
}

\begin{abstract}
Two experiments are reported in which the processing units involved in the reading of French polysyllabic words are examined. A comparison was made between units following the maximal onset principle (i.e., the spoken syllable) and units following the maximal coda principle (i.e., the basic orthographic syllabic structure $\{$ BOSS $\}$ ). In the first experiment, it took longer to recognize that a syllable was the beginning of a word (e.g., the FE of FETUS) than to make the same judgment of a BOSS (e.g., FET). The fact that a BOSS plus one letter (e.g., FETU) also took longer to judge than the BOSS indicated that the maximal coda principle applies to the units of processing in French. The second experiment confirmed this, using a lexical decision task with the different units being demarcated on the basis of color. It was concluded that the syllabic structure that is so clearly manifested in the spoken form of French is not involved in visual word recognition.
\end{abstract}

In order to recognize that a letter string has a meaning, a reader needs to gain access to the representation for this letter string in lexical memory, which provides the gateway to semantic information. A match has to be found between this stored lexical representation and the incoming sensory representation. The issue addressed here is how such a match is made. In particular, is the internal structure of the letter string utilized for accessing the lexicon and, if so, what is the nature of such a sublexical structure?

This question of the nature of the lexical processing unit in visual word recognition requires a determination of whether it is the phonological system or the orthographic system that is involved. Experimentally, this problem is addressed via the study of the role of phonological sublexical units versus orthographic sublexical units during visual word recognition. This debate is directly related to the question of whether the lexical access unit used for visual word recognition is similar to the one used for spoken word recognition or whether it is specific to the visuoorthographic processes involved in reading.

The answer to such a question could be different from one language to another, especially because the lexical access unit used for spoken word recognition has been shown to be different in different languages. For example, it appears that the syllable plays an important role in the perception, segmentation, and comprehension of spoken French (Cutler, 1995; Cutler \& Norris, 1988; Dupoux,

The research reported in this paper was supported by a grant awarded to the second author from the Australian Research Council. Correspondence concerning this article should be addressed to A. Rouibah, Institut des Sciences Cognitives, 67 boulevard Pinel, 69500 Bron, France (e-mail: rouibah@isc.cnrs.fr).
1993; Mehler, 1981), but not so obviously in spoken English (e.g., Bradley, Sánchez-Casas, \& García-Albea, 1993; Cutler, 1995; Cutler, Mehler, Norris, \& Segui, 1986). This is presumably due to the fact that the phonological system of these two languages is different. The English phonological system is not entirely regular, having two kinds of syllables, strong and weak. In comparison, French has a more regular phonological system for which all syllables have the same status.

If it is correct that the syllabic structure of a word is important for word recognition, it becomes necessary to define where the syllable boundary falls for any given word. Generally, a syllable can be analyzed into an onset, a nucleus, and a coda - for example, /skript/ (i.e., SCRIPT) has the onset $/ \mathrm{skr} /$, the nucleus $/ \mathrm{I} /$, and the coda $/ \mathrm{pt} /$. The syllabic structure of a language is then defined on the basis of a consonant/vowel template (Itô, 1988, 1989) that specifies the maximal number of consonants in the onset, vowels in the nucleus, and consonants in the coda. Given this definition, one should be able not only to identify an isolated syllable, but also to determine the syllabic boundaries within any given polysyllabic word.

In French, the syllable boundary appears clear-cut, following the maximal onset principle that has been proposed on linguistic grounds (e.g., Spencer, 1996). According to this principle, a consonant is positioned so that the maximal number of onsets occur in the word. For example, in the word /rutin/ (i.e., ROUTINE), the / $\mathrm{t} / \mathrm{be}$ comes the onset of the second syllable, rather than the coda of the first. However, in English, there are many cases where the boundary is poorly defined, most particularly when a short stressed vowel is followed by a single consonant. For example, is the syllabic structure of 
the word /pænık/ (i.e., PANIC) to be taken as /pæ+nIk/, $/$ pæn+rk/, or even /pæn+nik/?

The maximal onset principle would lead one to choose the first analysis because, in this case, the $/ \mathrm{n} /$ becomes the onset of the second syllable. The idea of ambisyllabicity (Spencer, 1996), however, would lead one to prefer the third analysis because it maintains $/ \mathrm{n} /$ as an onset, while avoiding having a syllable that ends in a short vowel. These two ways of breaking down a word into syllabic units are based on the phonological system of spoken alphabetic languages, with the former being typically adopted in experiments that examine syllabic processing (e.g., Cutler, 1995; Ferrand, Segui, \& Grainger, 1996).

An alternative way of seeing the syllable structure of polysyllabic words has been proposed by Taft (1979, 1987), although his focus was explicitly on the sublexical unit involved in reading. In complete violation of the maximal onset principle, Taft put forward the idea of a unit that maximizes the coda of the first syllable by drawing a structural boundary after all the consonants that follow the first vowels of the stem morpheme. This maximal coda principle (Taft \& Radeau, 1995) would lead one to consider that the syllabic structure of the word PANIC is PAN+IC, because, in this case, the inclusion of $\mathrm{N}$ maximizes the amount of information contained in the initial unit of the word. Taft (1979) called this initial unit the basic orthographic syllabic structure (BOSS), suggesting that it emerges from an orthographic analysis that ignores the phonological syllable structure of polysyllabic words. Thus, even for English words whose pronunciation seems to follow the maximal onset principle (e.g., /ru+ti:n/), the BOSS will include the coda (e.g., ROUT+INE). What this means is that, for English, the orthographic access units do not necessarily coincide with phonological units.

\section{Visual Processing of Syllabic Structure in English}

In support of the BOSS idea, Taft (1979) observed that when visually presented words are split on the screen by means of a physical gap, those divided at their BOSS (e.g., THUND ER) were associated with faster lexical decision times than those divided according to their phonologically defined syllable (e.g., THUN DER). Using several other splitting paradigms, such as the presentation of initial fragments for recognition (e.g., recognizing that THUN or THUND was the beginning of a word-namely, THUNDER), Taft (1987) replicated the preference for a BOSS analysis. Furthermore, he showed that it did not arise from the fact that the BOSS was more informative than the syllable because it had more letters. In particular, the chosen items were equally predictive of the final word on the basis of their syllable and BOSS (e.g., THUNDER is already uniquely defined by THUN), and also, there was no further enhancement of reaction times (RTs) when the initial fragment was made one letter longer than the BOSS (e.g., THUNDE).

There have been several other studies that have obtained results that are at least consistent with the BOSS idea (Inhoff, 1987; Luszcz, Bungey, \& Geffen, 1984; Prinzmetal, Treiman, \& Rho, 1987), but others that have totally failed to find any support (Jordan, 1986; Knuijt \& Assink, 1997; Lima \& Pollatsek, 1983; Seidenberg, 1987). The study by Lima and Pollatsek particularly raises problems, because it employed a paradigm similar to the one used by Taft $(1979,1987)$ and found no sign at all of a preference for the BOSS analysis over the syllable one.

In summary, whereas evidence for the BOSS effect is fairly weak in the reading of English, there is certainly no evidence that the phonologically defined syllable is involved in the recognition of visually presented words. This is hardly surprising, however, given that English speakers lack sensitivity to syllable structure even in spoken word processing (e.g., Cutler, 1995; Cutler et al., 1986). On the other hand, French has relatively clear syllable boundaries, and French speakers are sensitive to this fact (e.g., Cutler, 1995; Cutler \& Norris, 1988; Dupoux, 1993; Mehler, 1981), which means that the phonological syllable has a greater potential to be involved in visual word recognition for French than for English.

\section{Visual Processing of Syllabic Structure in French}

A study by Ferrand et al. (1996), using syllables as masked primes, revealed reliable facilitation in word, nonword, and picture naming when prime and target shared the first syllable, relative to a condition in which they shared a string of segments of equal length that was either longer or shorter than the first syllable. In contrast, there was no such syllable priming effect when a visual lexical decision task was used. This supported their hypothesis that the syllable priming effect arises during the creation of form representations required for overt French word naming, which is also consistent with the effects of syllable priming observed by Taft and Radeau (1995) in a task also requiring a naming response (to nonwords).

Because the Ferrand et al. (1996) study suggests that syllable priming does not affect lexical decision responses, one could argue that the syllable is not an orthographic access unit in French. It is possible, however, that the syllable priming effect would have been observed in the lexical decision task with a longer stimulus onset asynchrony (SOA) than the one used by Ferrand et al. - that is, when phonological processing comes into play. After all, with longer SOAs, phonological priming effects have been obtained in a number of studies using tasks for which lexical access was required (see, e.g., Ferrand \& Grainger, 1994; Rouibah, Tiberghien, \& Lupker, 1999).

Other than the study by Ferrand et al. (1996), little attention has been paid to the question of whether or not syllable effects can be observed in French visual word recognition tasks that do not require overt naming. There is support for syllables being access units in another language with clear syllabic structure-namely, Spanish (e.g., Carreiras, Alvarez, \& de Vega, 1993)—so one might have expected the same to be true in French. However, the results of Ferrand et al. suggest otherwise. Therefore, although spoken word recognition is sensitive to syllabic 
structure in French, this may not be true for visual word recognition. If it is the case that orthographic processing is independent of spoken word processing, one may not expect any preference for a syllabic analysis over a BOSS analysis in French.

In fact, a study carried out by Rouibah and Tiberghien (1994) gave some indication that the BOSS plays a role in the processing of written French. Rouibah and Tiberghien observed that when participants had to freely abbreviate spoken French disyllabic words, they preferentially produced abbreviations of the BOSS type ( $70 \%$ of the total production), whatever the structure of the syllable boundary was (e.g., one consonant at the syllable boundary, as in SOLEIL; two consonants at the syllable boundary, with one being the first syllable coda and one being the second syllable onset, as in COMBAT; or two consonants at the syllable boundary, forming the second syllable onset, as in LIVRET). This result suggests that the BOSS is a functional unit in French written production. Furthermore, because the purpose of abbreviations is to allow the original word to be retrieved efficiently, one could suggest that the BOSS has an important role to play in the process of lexical access. However, this hypothesis has not been directly tested yet. Furthermore, it is possible that the BOSS's emergence in the Rouibah and Tiberghien study was due to the fact that a BOSS-type abbreviation simply provides more information about the original word than does a syllable abbreviation on the basis of the amount of segmental overlap between the abbreviation and the target word.

\section{The Present Study}

The purpose of the present research was to compare the syllable and BOSS as processing units in reading French words. To be certain that any functional role observed for one of these sublexical units can be attributed to its structure and not merely to its informativeness, all of the chosen test words could be potentially retrieved with the same probability from their first syllable as from their BOSS. For example, VAM (a syllable) is as predictive as VAMP (a BOSS) of the French word VAMPIRE because VAM is always followed by a $P$ in French.

\section{EXPERIMENT 1}

Experiment 1 was run to determine whether visual presentation of a unit shorter than the whole word is sufficient to activate the lexical representation of that word. Establishing the optimal sublexical fragment for such activation would provide information about the structure of the lexical representation of polysyllabic words. Because Rouibah and Tiberghien (1994) observed that participants preferentially abbreviated French words by their BOSS and because an abbreviation is a word fragment from which the whole word is supposed to be retrieved, one can make the prediction that the BOSS will be preferred over the syllable as the activation unit. If this is the case, it means that the sublexical unit implicated in French visual word recognition is different from the one implicated in French spoken word recognition. On the other hand, it is possible that visual word recognition is simply a reflection of spoken word recognition in a different modality and that the first syllable will be the favored activation unit.

To determine which sublexical unit allows the more efficient access to lexical memory, Experiment 1 required participants to decide whether visually presented letter strings were or were not the beginning of real French words. This was one of the tasks used by Taft (1987) to support the importance of the BOSS in English. The letter strings used in this experiment could be the first syllable of a real word (e.g., SQUE, first syllable of SQUELETTE), the BOSS of a real word (e.g., SQUEL), the BOSS plus one letter of a real word (e.g., SQUELE), or a letter string which was not the beginning of any French word (e.g., SKUIL). If the first syllable is the more efficient lexical access unit, one would predict that the decision times will be faster when the letter string is the first syllable of a real word than when it is another fragment. On the other hand, if the more efficient unit is the BOSS, what should be observed is fastest decision times when the letter string corresponds to the BOSS of a real word.

\section{Method}

Participants. Thirty-six undergraduate students from the University of Grenoble, all native French speakers, participated in the experiment.

Materials. Twenty-four French words for which the first syllable was as predictive as the BOSS were used. That is, one and only one BOSS could be derived from the first syllable (e.g., for the first syllable FE there is only one possible BOSS, which is FET; hence, FEE is as predictive as FEET of the French words FETUS and F(ETAL). The first syllable, the BOSS and the BOSS plus one letter (e.g., F(ETU) were isolated from their original word and used as experimental stimuli. By definition, the 72 isolated word fragments were the beginning of real French words (see Appendix A). The three different kinds of word fragments determined the three experimental conditions: (1) the first syllable condition, (2) the BOSS condition, and (3) the BOSS +1 condition. Furthermore, 24 letter strings that were not the beginning of real French words were constructed; 8 of them were equivalent to the first syllable condition (e.g., LEE), 8 were equivalent to the BOSS condition (e.g., PUAR), and 8 were equivalent to the BOSS +1 condition (e.g., BIXTU). These letter strings, called nonword fragments, were used as fillers (see Appendix A).

Three lists of 48 stimuli were constructed by combining 24 word fragments with the 24 nonword fragments. Each list was composed of the first syllable of eight real words, the BOSS of eight different real words, the BOSS +1 of a further eight real words, and all of the 24 nonword fragments. The eight words used to extract one type of word fragment (e.g., first syllable) in one list were used to extract another type of word fragment (e.g., BOSS) in the second list and another type (e.g., BOSS+1) in the third list. The 48 stimuli of a list were presented in a different random order to each participant, with the constraint that the participants did not see more than 3 word fragments (or nonword fragments) in a row. Each participant was presented with one and only one of the three lists. All the items were presented in lowercase.

Procedure. The participants sat in front of the screen of a Macintosh Quadra 700 computer. A fixation point was presented in the 
center of the screen for $504 \mathrm{msec}$, after which the screen remained blank for $203 \mathrm{msec}$. A fragment was then presented in the center of the screen for $700 \mathrm{msec}$.

The participants were instructed to decide whether the presented fragment was or was not the beginning of a French word and to respond as quickly and as accurately as possible. Responses were made by pressing a designated key on the computer keyboard with the dominant hand when the response was yes, and a different designated key with their other hand when the response was no.

\section{Results}

RTs to correct yes responses and error rates were analyzed using analyses of variance (ANOVAs), where both participants $\left(F_{1}\right)$ and items $\left(F_{2}\right)$ were separately treated as random factors. Figure 1 presents the RTs and error rates for the three conditions of the fragment completion task.

Error rate analysis. The error rates observed in the three experimental conditions were not significantly different from each other (first syllable, 9.37\%; BOSS, $8.67 \%$; BOSS plus one letter, $9.02 \%$ ).

Reaction time analysis. A significant effect of experimental condition was observed both by participants $\left[F_{1}(2,70)=47.017, M S_{\mathrm{e}}=33,888, p<.01\right]$ and by items $\left[F_{2}(2,69)=15.085, M S_{\mathrm{e}}=21,864, p<.01\right]$. This effect was due to the fact that responses to the BOSS fragments were significantly faster $(655 \mathrm{msec})$ than those to the syllable fragments [716 msec; $F_{1}(1,70)=93.01, M S_{\mathrm{e}}=$ $720.76, p<.01 ; F_{2}(1,69)=29.76, M S_{\mathrm{e}}=1,449.4, p<$ $.01]$ and also faster than those to the BOSS+1 letter fragments [691 msec; $F_{1}(1,70)=32.47, M S_{\mathrm{e}}=720.76, p<$ $\left..01 ; F_{2}(1,69)=10.75, M S_{\mathrm{e}}=1,449.4, p<.01\right]$. Furthermore, responses to the BOSS+1 letter fragments were faster than those to the syllable fragments $\left[F_{1}(1,70)=\right.$ $15.57, M S_{\mathrm{e}}=720.76, p<.01 ; F_{2}(1,69)=4.74, M S_{\mathrm{e}}=$ $1,449.4, p<.05]$.

\section{Discussion}

The first point to note from Experiment 1 is that a word fragment provides sufficient information for the activation of the mental representations of the full word. The participants were able to decide quite accurately that a letter string was the beginning of a real word, whatever the word fragment was (first syllable, BOSS, or BOSS plus one letter). However, the three word fragment types used in this experiment led to different decision times. Most important, it appears that the presentation of the BOSS of a word led to a faster recognition than did the presentation of the first syllable. This is exactly the same result as that obtained by Taft (1987) using this fragment judgment task in English. The experiment suggests not only that the BOSS is a more important unit in visual lexical processing of French than is the syllable but also that the difference is considerable.

It cannot be argued that this finding is simply a result of the BOSS fragment's narrowing down the set of potential candidates more than does the syllable, because the number of possible completions is the same for the two conditions. Furthermore, it cannot be argued that the BOSS simply provides more bottom-up information about the word to be fed into the lexical activation system, because when a letter is added to the BOSS fragment (i.e., BOSS+1), there is no further benefit. If anything, the BOSS +1 fragment was more predictive than the BOSS fragment: Although the stimuli were designed so that the same number of words began with the BOSS as with the first syllable, it was possible for there to be more than one such word, as in the case of FETUS and FETAL. Therefore, the BOSS +1 narrows down the possibilities more than the other two conditions (i.e., only FETUS begins with FETU), yet the BOSS +1 condition certainly did not pro-
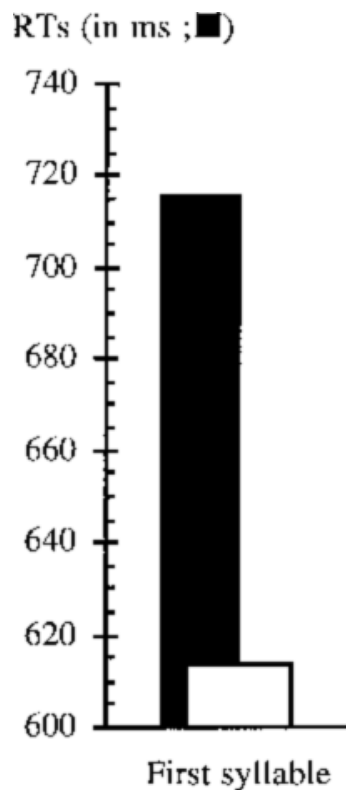

\section{Error rates (in \%;口)}

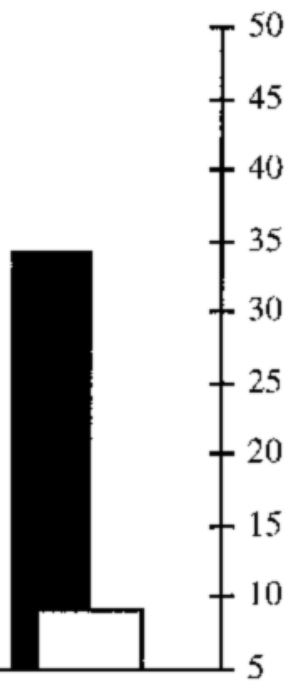

BOSS+1

Figure 1. Fragment completion times (RTs) and error rates obtained with three different types of word fragments in Experiment 1. 
vide faster RTs than did the BOSS. In fact, it was actually a disadvantage to have an extra letter beyond the BOSS, with RTs becoming longer.

Why should the provision of an extra letter beyond the BOSS prove detrimental to the fragment judgment? Perhaps, whereas the BOSS (e.g., FET) serves to activate one or more lexical representations (FETUS and FETAL), when there is information beyond the BOSS (as with the $\mathrm{U}$ of FETU), it is necessary to ascertain whether this information is compatible with those representations. For example, if one is presented with the fragment FETO, a $n o$ response would be required even though it contains an existing BOSS.

It seems that the evidence for the BOSS's being the optimal unit for visually accessing the word in French is the same as for English. However, although the task used in Experiment 1 requires the activation of lexical representations, it might be argued that fragment completion is achieved via some form of recognition strategy that is different from what is normally used in the presence of the whole word. Although it is hard to see why such a strategy, if it exists, would favor a BOSS analysis, Experiment 2 was designed in a way that avoids this potential concern.

\section{EXPERIMENT 2}

In this experiment, the participants were presented with whole words split on the screen after their first syllable, their BOSS, or their BOSS+1 (cf. Taft, 1979, 1987). The splitting technique made use of color to mark off the sublexical units and, as such, did not disrupt the overall shape of the word. The initial unit of the word was presented in black with the rest in gray. In this way, the syllable, BOSS or BOSS+1 could be highlighted (e.g., FETUS, FETUS, FETUS, respectively). In a lexical decision task, the sublexical unit that is most efficient in activating lexical information should lead to faster RTs when highlightedin black.

\section{Method}

Participants. Thirty-six undergraduate native French speakers from the University of Grenoble participated in the experiment. None had been included in the first experiment.

Materials. The 24 French words used in Experiment 1, for which the first syllable was as predictive as the BOSS, were again used in this experiment. These words were written in two different colors. The beginning of the word was written in black, and the remaining letters, at the end of the word, in gray, so that a presented word was physically divided into two units without the overall shape of the word being disrupted. The 24 words were divided by color according to the three experimental conditions: (1) first syllable in black, (2) BOSS in black, and (3) BOSS+1 in black. Furthermore, 24 pseudowords were constructed. As with the words, the pseudowords were written in two different colors, the beginning in black and the remaining letters in gray. A third of the pseudowords had a black first syllable (e.g., LEETAS), a third had a black BOSS (e.g., PUAR AL), and a third had a black BOSS+1 (e.g., VIXTULE).

Three lists of 48 stimuli were constructed by combining the 24 words and 24 pseudowords (see Appendix B). Each list was composed of 8 words for which the first syllable was in black, 8 other words for which the BOSS was in black, and 8 other words for which the BOSS+1 was in black. The pseudowords were similarly divided among the three lists. The 8 words and the 8 pseudowords that had one particular part in black (e.g., the first syllable) in one list had another part in black (e.g., the BOSS) in a second list and another part in black (e.g., the BOSS+1) in the third list. The 48 stimuli of a list were presented in a different random order to each participant, with the constraint that the participants did not see more than 3 stimuli in a row having the same part in black. Each participant was presented with one and only one of the three lists. All the items were presented in lowercase.

Procedure. The procedure was the same as that in Experiment 1, except that a lexical decision response was required. That is, the participants had to decide whether the presented letter string was or was not a real French word.

\section{Results}

RTs to correct yes responses and error rates were analyzed using ANOVAs in which both participants $\left(F_{1}\right)$ and items $\left(F_{2}\right)$ were separately treated as random factors. Figure 2 presents the mean lexical decision responses and error rates for the three conditions of Experiment 2.

Error rate analysis. The error rates observed in the three experimental conditions were not significantly different from each other (first syllable, 10.41\%; BOSS, $10.07 \%$; BOSS plus one letter, $11.11 \%$ ).

Reaction time analysis. A significant effect of experimental condition was observed both by participants $\left[F_{1}(2,70)=61.416 ; M S_{\mathrm{e}}=18,891 ; p<.01\right]$ and by items $\left[F_{2}(2,69)=15.843 ; M S_{\mathrm{e}}=13,103 ; p<.01\right]$. When words were split according to the BOSS analysis, RTs were faster $(615 \mathrm{msec})$ than when they were split according to the syllabic analysis $\left[661 \mathrm{msec} ; F_{1}(1,70)=122.33\right.$, $M S_{\mathrm{e}}=307.6, p<.01 ; F_{2}(1,69)=31.60, M S_{\mathrm{e}}=827.04$, $p<.01]$. The mean of the RTs for the BOSS+1 condition $(636 \mathrm{msec})$ fell in between the other two conditions $\left[F_{1}(1,70)=24.19, M S_{\mathrm{e}}=307.6, p<.01\right.$, and $F_{2}(1,69)=$ $6.53, M S_{\mathrm{e}}=827.04, p<.05$, for BOSS+1 vs. BOSS; $F_{1}(1,70)=37.72, M S_{\mathrm{e}}=307.6, p<.01$, and $F_{2}(1,69)=$ $9.40, M S_{\mathrm{e}}=827.04, p<.01$, for BOSS+1 vs. first syllable].

\section{Discussion}

Once again, there is very strong evidence here for the BOSS's being a functional unit of lexical processing when French is read. Exactly the same pattern of results was obtained as in Experiment 1, and again, there can be no argument made about the predictiveness of the highlighted part of the word, because the BOSS was no more predictive of the word than were the other two units.

Moreover, even if the participants were presented with whole words, they still preferentially used the BOSS to make their lexical decisions. One could ask, then, why the word recognition process would not use the full orthographic expression of a word in its quest for a lexical entry, but would use a slightly smaller unit (the BOSS) instead. One possible explanation is that the BOSS analysis by readers is partly motivated by an attempt to break down the polysyllabic word into manageably sized units (i.e., monosyllables). Because of the inclusion of the coda, the BOSS has an internal structure that is more similar 


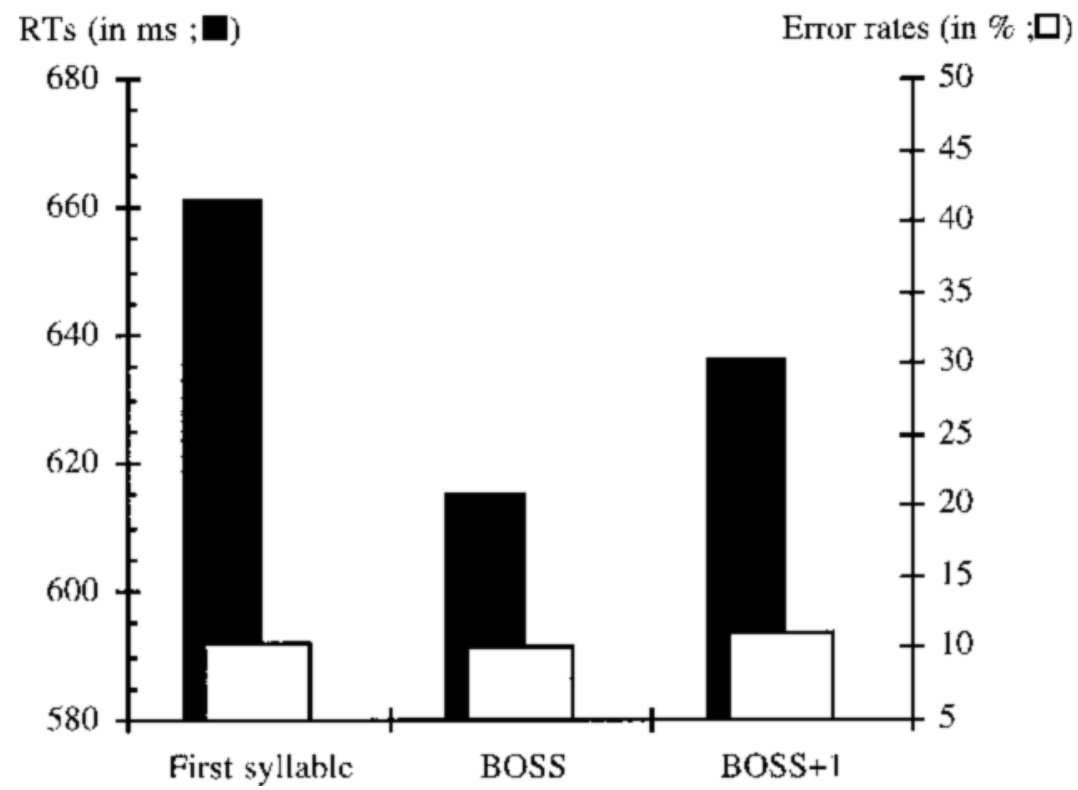

Figure 2. Mean lexical decision times (RTs) and error rates obtained for the three conditions in Experiment 2.

to monosyllabic short French words than is the first syllable. Indeed, $67 \%$ of the three-letter length and $61 \%$ of the four-letter length French monosyllabic words end with a consonant (Content, Mousty, \& Radeau, 1990). It is not the case, however, that words ending with a consonant are more usual in French than words ending in a vowel (see Appendix A). That is, the BOSS unit seems similar to real monosyllabic short words, but not to French words in general. It is possible, then, that one reason why the BOSS seems important in French visual word recognition is because it allows a lexical access mediated by a monosyllable-like unit.

One could argue, however, that it is not the BOSS, as a unit, that is used for lexical processing, but a sublexical structure that corresponds to the initial part of a real word, with the constraint that this part ends with a consonant (or a consonant cluster). That is, that any wordinitial part having a CVC internal structure could play the role of lexical access unit. If this is the case, not only the BOSS unit would lead to faster decision times, but also the first CVC syllable of a word. To make sure that this alternative explanation does not account for the BOSS effects obtained in the two experiments, it is necessary to make certain that first syllables having a CVC structure

Table 1

Mean Decision Times (RTs, in Milliseconds) Obtained With the First Syllables Having a CVC Structure Versus Those Having a CV Structure in Experiments 1 and 2
Experiment 1

Fragment Completion

RT

713

721
Experiment 2 Lexical Decision
CVC structure ("sanc")

CV structure ("tzi")

\begin{tabular}{rrrr}
$S D$ & & RT & $S D$ \\
\hline 91 & & 656 & 92 \\
101 & & 669 & 70
\end{tabular}

do not lead to faster decision times than first syllables having a CV structure. Post hoc statistical analyses were conducted to test this alternative hypothesis.

\section{Post Hoc Analyses}

RTs to correct yes responses were analyzed using ANOVAs in which both participants $\left(F_{1}\right)$ and items $\left(F_{2}\right)$ were separately treated as random factors. These ANOVAs were run on the first syllable item data subset, teasing apart the first syllables ending in a vowel (8 syllables) from those ending in a consonant (16 syllables). Table 1 presents the mean decision responses for the two conditions (CV vs. CVC) of Experiments 1 and 2.

The difference between the two conditions was not significant either in Experiment $1\left[F_{1}(1,35)=0.235\right.$, $\left.M S_{\mathrm{e}}=1,300 ; F_{2}(1,22)=0.039, M S_{\mathrm{e}}=68\right]$ or in Experiment $2\left[F_{1}(1,35)=1.031, M S_{\mathrm{e}}=3,200 ; F_{2}(1,22)=\right.$ $\left.3.826, M S_{\mathrm{e}}=3,888\right]$. That is, decision responses were not significantly faster when presented with a word's first syllable having a CVC internal structure than when presented with a word's first syllable having a CV internal structure. So, the BOSS advantage over the first syllable or the BOSS plus one letter does not seem to be due to the fact that the BOSS always ends with a consonant, even though the BOSS has an internal structure that is very similar to monosyllabic short French words.

\section{GENERAL DISCUSSION}

The results of the present experiments can be summed up quite succinctly. The BOSS seems to be the sublexical unit that allows the most rapid and accurate access to lexical representations when visually presented French words are processed. In both experiments, the observed 
decision times were faster when a word fragment of the BOSS type was available than when a word fragment of the syllable type or the BOSS plus one letter type was available. Moreover, with the kind of words used in the present experiments, the BOSS and the first syllable provided the same amount of information about the whole word-that is, each of the two sublexical units was as predictive as the other of the word. One cannot argue that the difference that is observed between these two units is due to the size of the segmental overlap between a word and its fragment, because adding one more letter to the BOSS provided no further advantage and, on the contrary, was actually detrimental to processing, even though the BOSS+1 fragment was sometimes more predictive of the original word than was the BOSS fragment.

One could suggest that the BOSS effects obtained in the two experiments could be due to the similarity between this subword unit and legal words. This interpretation could give a good account of the obtained results only if the BOSS unit is more similar to French words than the syllable or the BOSS +1 units. In particular, there is a difference between the BOSS fragment and the other two fragments. That is, BOSS fragments always end with a consonant, whereas BOSS +1 fragments and firstsyllable fragments often end with a vowel. However, it is not the case that words ending in a vowel are particularly unusual in French, as compared with words ending in a consonant. Moreover, the last-letter lexical frequency (Content \& Radeau, 1988) is similar for the three kinds of fragments used in the two experiments (see Appendix A). It cannot be argued, then, that the BOSS is more "wordlike" than the syllable or the BOSS+1 because of its ending letter. What can be argued, however, is that polysyllabic words are broken down into monosyllable-likeunits and that the BOSS maximizes the size of the all-important first unit.

From the present study, it can be concluded that the internal orthographic structure of a French word plays an important role in the visual recognition of that word, and the experiments reported here elucidate what that structure is: one that maximizes the coda.

Another important conclusion can also be drawn. The BOSS superiority effect observed in both visual recognition experiments suggests that the sublexical unit used for French visual word recognition is different from that used for French spoken word recognition. This is consistent with the study of Ferrand et al. (1996), which failed to obtain any first-syllable priming effect in a lexical decision task, although observing such an effect in a naming task. In French speech perception and production, the syllable defined in terms of the maximal onset principle has been shown consistently to be a critical and functional unit of processing (Cutler, Mehler, Norris, \& Segui, 1992; Ferrand et al., 1996; Meyer, 1990; Segui, 1984). The present research suggests, however, that when it comes to visual word recognition, such a syllabic structure seems to be less useful than one defined in terms of maximal coda (i.e., one that maintains the BOSS as a unit of lexical representation).

The assumption has been made until now that the BOSS must be an orthographically based unit because it is incongruent with the phonological structure of the word. However, another possibility exists. Although the spoken realization of a disyllabic word may position a medial consonant as the onset of the second syllable (giving, for example, $/ \mathrm{ru}+\mathrm{tin} /$ ), it is possible that this is only a feature of the surface phonetic manifestation of the word and not of the underlying phonemic representation from which the surface form is generated. That is, the orthographic representation of a word may be associated with a phonological representation that is not the surface form, but from which the surface form can be generated (see Taft \& van Graan, 1998). It may be that this phonological representation follows the maximal coda principle (giving/rut+in/) and resyllabification occurs when the spoken output is generated from this form. If this is correct, the observed BOSS effect could actually be interpreted as occurring within the phonological system.

It is interesting to note that coarticulation effects have been reported across phonetic syllable boundaries in French (e.g., Baum \& Waldstein, 1991; Fowler, 1981; Recasens, 1984, 1987)—that is, the perception and production of a consonant is partially influenced by its preceding vowel, and vice versa. This suggests that the individual syllables of the spoken word are not entirely discrete entities, and such an observation might be seen as being consistent with the idea that the spoken form has been generated from a representation that couples the vowel with its following consonant(s)—namely, a BOSS - and that a vestige of this remains in the surface manifestation.

Whether the BOSS should be interpreted as a purely orthographic unit or as an abstract phonological one, what is apparent from the research reported here is that visual word recognition in French involves a structured representation of the word in lexical memory and this structure is not the same as that found in its spoken form. The units of visual word processing are not merely the orthographic analogues of the units of spoken word processing.

\section{REFERENCES}

Baum, S. R. \& WAldstein, R. S. (1991). Perseveratory coarticulation in the speech of profoundly hearing-impaired and normally hearing children. Journal of Speech \& Hearing Research, 34, 1286-1292.

Bradley, D. C., Sánchez-Casas, R. M., \& García-Albea, J. E. (1993). The status of the syllable in the perception of Spanish and English. Language \& Cognitive Processes, 8, 197-233.

Carreiras, M., Alvarez, C. J., \& DE Vega, M. (1993). Syllable frequency and visual word recognition in Spanish. Journal of Memory \& Language, 32, 766-780.

Content, A., Mousty, P., \& Radeau, M. (1990). Brulex: Une base de données lexicales informatisée pour le français écrit et parlé [Brulex: A computerized lexical database for written and spoken French]. L'Année Psychologique, 90, 551-566.

Content, A., \& Radeau, M. (1988). Données statistiques sur la structure orthographiquedu français/Statistical data on the orthographical 
structure of French. Cahiers de Psychologie Cognitive/Current Psychology of Cognition, 8, 399-404.

Cutler, A. (1995). Spoken word recognition and production. In J. L. Miller \& P. D. Eimas (Eds.), Speech, language and communication (pp. 97-136). San Diego: Academic Press.

Cutler, A., Mehler, J., Norris, D., \& Segui, J. (1986). The syllable's differing role in the segmentation of French and English. Journal of Memory \& Language, 25, 385-400.

Cutler, A., Mehler, J., Norris, D., \& Segui, J. (1992). The monolingual nature of speech segmentation by bilinguals. Cognitive Psychology, 24, 381-410.

Cutler, A., \& Norris, D. (1988). The role of strong syllables in segmentation for lexical access. Journal of Experimental Psychology: Human Perception \& Performance, 14, 113-121.

Dupoux, E. (1993). The time course of prelexical processing: The syllabic hypothesis revisited. In G. T. M. Altmann \& R. Shillcock (Eds.), Cognitive models of speech processing: The second Sperlonga meeting (pp. 81-114). Hillsdale, NJ: Erlbaum.

FERRAND, L., \& GRAinger, J. (1994). Effects of orthography are independent of phonology in masked form priming. Quarterly Journal of Experimental Psychology, 47A, 365-382.

Ferrand, L., Segui, J., \& Grainger, J. (1996). Masked priming of word and picture naming: The role of syllabic units. Journal of Memory \& Language, 35, 708-723.

Fowler, C. A. (1981). Production and perception of coarticulation among stressed and unstressed vowels. Journal of Speech \& Hearing Research, 24, 127-139.

InHOFF, A. W. (1987). Parafoveal word perception during eye fixations in reading: Effects of visual salience and word structure. In M. Coltheart (Ed.), Attention and performance XII: The psychology of reading (pp. 403-418). Hillsdale, NJ: Erlbaum.

ITô, J. (1988). Syllabic theory in prosodic phonology. New York: Garland Press.

ITô, J. (1989). A prosodic theory of epenthesis. Natural Language \& Linguistic Theory, 7, 217-259.

JoRDAN, T. R (1986). Testing the BOSS hypothesis: Evidence for positioninsensitive orthographic priming in the lexical decision task. Memory \& Cognition, 14, 523-532.

KnuiJt, P. P. N. A., \& Assink, E. M. H. (1997). Morphographic units in Dutch polysyllabic words: In search of the body of the BOSS. Scientific Studies of Reading, 1, 99-117.

Lima, S. D., \& PollatseK, A. (1983). Lexical access via an orthographic code? The basic orthographic syllabic structure (BOSS) reconsidered. Journal of Verbal Learning \& Verbal Behavior, 22, 310-332.
Luszcz, M. A., Bungey, J., \& Geffen, G. (1984). Orthographicmorphemic factors in reading: A developmental study. Australian Journal of Psychology, 36, 355-365.

MeHLER, J. (1981). The role of syllables in speech processing: Infant and adult data. Philosophical Transactions of the Royal Society: Series $B, \mathbf{2 9 5}, 333-352$.

Meyer, A. S. (1990). The time course of phonological encoding in language production: The encoding of successive syllables of a word. Journal of Memory \& Language, 29, 524-545.

Prinzmetal, W., Treiman, R, \& RHo, S. H. (1987). How to see a reading unit. Journal of Memory \& Language, 25, 461-475.

RECASENS, D. (1984). Vowel-to-vowel coarticulation in Catalan VCV sequences. Journal of the Acoustical Society of America, 76, 1624-1635.

ReCasens, D. (1987). An acoustic analysis of V-to-C and V-to-V coarticulatory effects in Catalan and Spanish VCV sequences. Journal of Phonetics, 15, 299-312.

Rouibah, A., \& Tiberghien, G. (1994). Emergence d'une unité sublexicale au cours d'une tâche d'abréviation [Emergence of a sublexical unit in abbreviation production]. L'Année Psychologique, 94, 211-232.

Rouibah, A., Tiberghien, G., \& Lupker, S. J. (1999). Phonological and semantic priming: Evidence for task-independent effects. Memory \& Cognition, 27, 422-437.

SEgUI, J. (1984). The syllable: A basic perceptual unit in speech perception? In H. Bouma \& D. G. Bouwhuis (Eds.), Attention and performance X: Control of language processes (pp. 165-181). Hillsdale, $\mathrm{NJ}$ : Erlbaum.

SEIDENBERG, M. S. (1987). Sublexical structures in visual word recognition: Access units or orthographic redundancy? In M. Coltheart (Ed.), Attention and performance XII: The psychology of reading (pp. 245-263). Hillsdale, NJ: Erlbaum.

Spencer, A. (1996). Phonology. Oxford, U.K.: Blackwell.

TAFT, M. (1979). Lexical access via an orthographic code: The basic orthographic syllabic structure (BOSS). Journal of Verbal Learning \& Verbal Behavior, 18, 21-39.

TAFT, M. (1987). Morphographic processing: The BOSS re-emerges. In M. Coltheart (Ed.), Attention and performance XII: The psychology of reading (pp. 265-279). Hillsdale, NJ: Erlbaum.

TAFT, M., \& RADEAU, M. (1995). The influence of the phonological characteristics of a language on the functional units in reading: A study in French. Canadian Journal of Experimental Psychology, 49, 330-346.

TAFT, M., \& VAN GRAAN, F. (1998). Lack of phonological mediation in a semantic categorization task. Journal of Memory \& Language, 38, 203-224.

Word Fragments and Fillers Used as Stimuli in Experiment 1

\begin{tabular}{|c|c|c|c|c|c|c|c|}
\hline \multirow[b]{2}{*}{$\begin{array}{l}\text { French } \\
\text { Words }\end{array}$} & \multicolumn{6}{|c|}{ Word Fragments } & \multirow[b]{2}{*}{ Fillers } \\
\hline & $\begin{array}{c}\text { First } \\
\text { Syllable }\end{array}$ & $\begin{array}{l}\text { Last Letter } \\
\text { Frequency }\end{array}$ & BOSS & $\begin{array}{l}\text { Last Letter } \\
\text { Frequency }\end{array}$ & $\begin{array}{c}\text { BOSS+ } \\
\text { One Letter } \\
\end{array}$ & $\begin{array}{l}\text { Last Letter } \\
\text { Frequency }\end{array}$ & \\
\hline fœtus & $f œ$ & 9,420 & fœt & 7,906 & fœtu & 3,563 & $1 œ$ \\
\hline juxtaposer & jux & 1,812 & juxt & 7,906 & juxta & 2,099 & bix \\
\hline ketchup & ket & 10,507 & ketch & 683 & ketchu & 2,628 & xut \\
\hline klaxon & kla & 1,087 & klax & 2,227 & klaxo & 2,147 & kna \\
\hline lymphatique & lym & 2,174 & lymph & 683 & lympha & 1,192 & jyn \\
\hline onctueux & onc & 6,884 & onct & 7,906 & onctu & 3,563 & unv \\
\hline philosophe & phi & 9,058 & phil & 3,341 & philo & 2,147 & phu \\
\hline poêlon & poê & 0 & poêl & 3,341 & poêlo & 2,147 & poa \\
\hline psalmodie & psal & 3,341 & psalm & 683 & psalmo & 1,284 & ptolm \\
\hline psychiatre & psy & 1,449 & psych & 683 & psychi & 1,620 & psech \\
\hline puéril & pué & 4,348 & puér & 5,011 & puéri & 2,196 & puar \\
\hline sanction & sanc & 3,786 & sanct & 8,638 & sancti & 1,620 & vonct \\
\hline sceptique & scep & 1,114 & scept & 8,638 & scepti & 1,620 & stapt \\
\hline sculpteur & scul & 3,341 & sculpt & 8,863 & sculpte & 37,419 & scolpt \\
\hline shampooing & sham & 1,114 & shamp & 293 & shampo & 1,284 & shinp \\
\hline squelette & sque & 27,506 & squel & 3,563 & squele & 33,741 & skuil \\
\hline structure & struc & 781 & struct & 8,863 & structu & 2,259 & sproctu \\
\hline tempête & tem & 2,174 & temp & 1,114 & tempê & 98 & wompé \\
\hline texture & tex & 1,812 & text & 7,906 & textu & 3,563 & vixtu \\
\hline
\end{tabular}


APPENDIX A (Continued)

\begin{tabular}{lccccccc}
\hline & \multicolumn{7}{c}{ Word Fragments } \\
\cline { 2 - 6 } \multicolumn{1}{c}{ French } & First & Last Letter & & Last Letter & BOSS+ & Last Letter & \\
\hline tympan & Syllable & Frequency & BOSS & Frequency & One Letter & Frequency & Fillers \\
tzigane & tym & 2,174 & tymp & 1,114 & tympa & 2,099 & vympu \\
vampire & vam & 9,058 & tzig & 1,002 & tziga & 2,099 & tzuge \\
zombie & zom & 2,174 & vamp & 1,114 & vampi & 2,196 & tumpa \\
kleptomane & klep & 1,114 & zomb & 223 & zombi & 2,196 & zimpu \\
Mean & & 4,517 & & 8,638 & klepto & 1,284 & klipsa \\
\hline
\end{tabular}

Note-The last letter lexical frequency of a word fragment (syllable, BOSS, or BOSS plus one letter) is the lexical frequency of a particular character in French (Content \& Radeau, 1988). This frequency measure takes into account the position of the character in the letter string. Furthermore, a word's length is included in the measure. That is, the frequency of each letter was calculated separately for words containing 3-15 letters. This measure can help to answer such a question as, what is the frequency of a given letter in a particular position in a word having such number of characters?

\begin{tabular}{|c|c|c|c|}
\hline Words & $\begin{array}{c}\text { Word } \\
\text { Frequency }\end{array}$ & $\begin{array}{l}\text { Syllable } \\
\text { Length }\end{array}$ & Pseudowords \\
\hline fœtus & 2.17 & 2 & lœtas \\
\hline juxtaposer & 2.37 & 4 & bixtopuler \\
\hline ketchup & - & 2 & xutchip \\
\hline klaxon & 2.30 & 2 & knaxan \\
\hline lymphatique & 2.08 & 3 & jympholuque \\
\hline onctueux & 2.52 & 3 & unsteau \\
\hline philosophe & 3.87 & 3 & phuchautre \\
\hline poêlon & 1.25 & 2 & poacin \\
\hline psalmodie & - & 3 & ptolmidot \\
\hline psychiatre & 2.51 & 3 & psechoutre \\
\hline puéril & 3.32 & 2 & puaral \\
\hline sanction & 2.93 & 2 & vonction \\
\hline sceptique & 3.05 & 2 & staptaque \\
\hline sculpteur & 3.17 & 2 & scolptin \\
\hline shampooing & 1.47 & 2 & shinpau \\
\hline squelette & 2.99 & 2 & skuilette \\
\hline structure & 3.80 & 2 & sprocture \\
\hline tempête & 3.48 & 2 & wompéte \\
\hline texture & 2.17 & 2 & vixtule \\
\hline tympan & 2.26 & 2 & vympun \\
\hline tzigane & 2.24 & 2 & tzugone \\
\hline vampire & 2.36 & 2 & tumpare \\
\hline zombie & - & 2 & zimpie \\
\hline kleptomane & - & 3 & klipsaline \\
\hline Mean & 2.616 & 2.33 & \\
\hline$S D$ & 0.701 & 0.56 & \\
\hline
\end{tabular}

Note-The word frequency corresponds to the logarithm of the frequency of occurrence found in the French database BRULEX (Content, Mousty, \& Radeau, 1990).

(Manuscript received June 22, 1999;

revision accepted for publication July 27, 2000.) 